\title{
Tissue Engineering and Organ Structure: A Vascularized Approach to Liver and Lung
}

\author{
DAVID M. HOGANSON, HOWARD I. PRYOR II, AND JOSEPH P. VACANTI \\ Department of Pediatric Surgery, Harvard Medical School, Boston, MA 02114
}

\begin{abstract}
Over the past two decades, great strides have been made in the field of tissue engineering. Many of the initial attempts to develop an engineered tissue construct were based on the concept of seeding cells onto an avascular scaffold. Using advanced manufacturing technologies, the creation of a preformed vascular scaffold has become a reality. This article discusses some of the issues surrounding the development of such a vascular scaffold. We then examine of the challenges associated with applying this scaffold technology to two vital organ constructs: liver and lung. (Pediatr Res 63: 520-526, 2008)
\end{abstract}

$I^{n}$ 1985, we hypothesized that a living vital organ could be rationally designed and built for human therapy from cells and degradable polymer scaffolding. This was based on only two pieces of previous work: 1) an acellular artificial dermis by Yannas and Burke (1); and 2) a vascular conduit of contracted collagen and vascular cells (2).

Our first reports described the formation of hepatic, intestinal, and pancreatic tissue $(3,4)$. In the ensuing $22 \mathrm{y}$, the fields of Tissue Engineering and Regenerative Medicine have become established and several tissues are available for human trials or use. In 1998, to overcome the problem of sufficient functional mass for human therapy, we hypothesized that we could build a vasculature as part of the tissue-engineered organ which would provide immediate exchange of oxygenand nutrient-rich blood to the full volume of engineered tissue, much as a transplanted organ functions today. Summarized below are the most recent developments toward an engineered vascularized tissue with emphasis on liver and lung.

\section{VASCULARIZED SCAFFOLD FOR SOLID ORGAN TISSUE ENGINEERING}

The fundamental challenge of developing a tissue for therapeutic use is scaling up the growth of cells from a culture dish to a three-dimensional scaffold. Multilayer cellular constructs are achievable on flat sheets or thin porous scaffolds. However, the creation of tissues for solid organ transplantation must overcome the limited distance of oxygen diffusion.

Received November 2, 2007; accepted December 6, 2007.

Correspondence: Joseph P. Vacanti, M.D., Chief of Pediatric Surgery, Massachusetts General Hospital, 55 Fruit Street WRN 11-1151, Boston, MA 02114; e-mail: jvacanti@partners.org

D.M.H. is supported by NIH NRSA F32 Grant: NIH 1 F32DK076349-01 Biliary morphogenesis and bile canaliculi integration. H.I.P. is supported by NIH NRSA T32 Grant: NIH T32DK07754-09 Research Training in Alimentary Tract Surgery. BioEngine Inc. Boston, MA.

D.M.H. and H.I.P. contributed equally to this work.
One approach is centered on angiogenesis, or the selfassembly of a vascular network within a scaffold by endothelial and smooth muscle cells. Although on a small scale this is achievable, this approach develops too slowly to support the mass of tissue that is required for an organ transplant, such as a liver. The Tissue Engineering and Organ Fabrication Laboratory at Massachusetts General Hospital proposed the creation of a scaffold with an integrated vascular network $(5,6)$. A capillary-like vascular network within a three-dimensional scaffold can deliver oxygenated blood to within several hundred micrometers of all cells in the scaffold. These vascular networks are designed to replicate features of a capillary network within the bounds of what can be manufactured. Initial work centered on the utilization of photolithography techniques to create molds of capillary-like networks (7-12). The vascular networks of these original molds were designed to have arterial pressure drop across the network with physiologic shear stress in the channels. These molds were used to create polymer based vascular networks, which could be seeded with endothelial cells (8). A second generation vascular network for a liver scaffold is shown ${ }^{1}$ in Fig. 1 (13).

The vascular network is adjacent to parenchymal cells of the specific organ (i.e., hepatocytes). A thin porous membrane in the scaffold allows the supply of oxygen and nutrients from the vascular network to the parenchymal cells and also removes waste products. A cross-sectional scanning electron microscope image of this scaffold design without cells is shown in Fig. 2. The posts are structural supports to maintain the desired height of the parenchymal chamber. Within this concept, the strategy has been to develop a scaffold with an integrated capillary-like vascular network, which can support a small amount of tissue. The planar network and scaffold can then be expanded by stacking and in parallel arrangements to create the necessary size of tissue or organ.

Recent developments by other groups in this area have focused on improving the design of the vascular networks to better mimic natural vessels and capillary beds. Zhou et al. hypothesized a generalized model of the minimum energy principle of natural vascular networks originally proposed by Murray $(14,15)$. This theoretical model defines scaling laws of a vascular network and has been validated by comparing it to morphologic data on several native human and animal vascular networks (16). This proposed scaling law defines relationships between the length,

Abbreviations: HepG2, hepatocellular carcinoma cell line; MSC, mesenchymal stem cells 


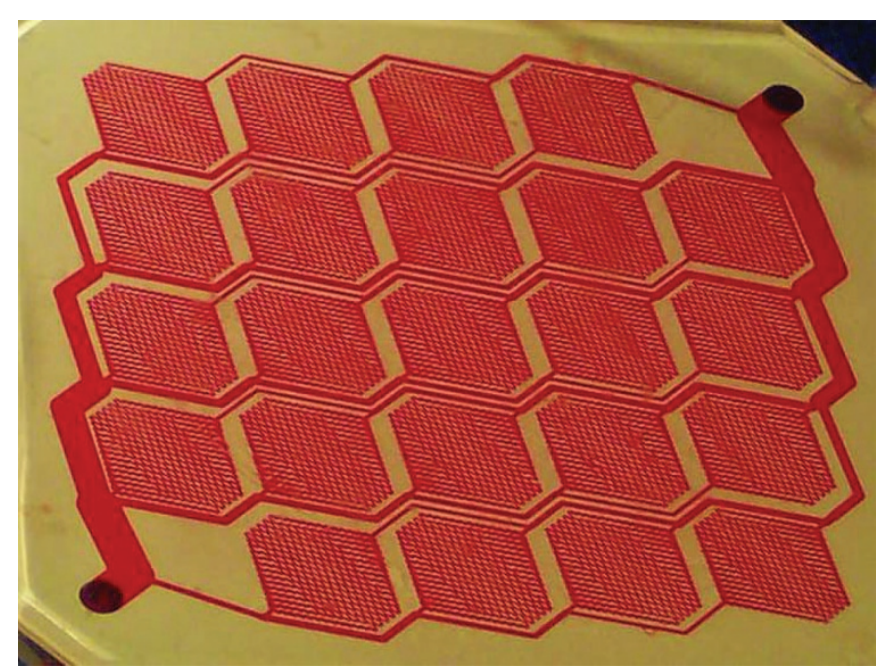

Figure 1. Second generation vascular network design.

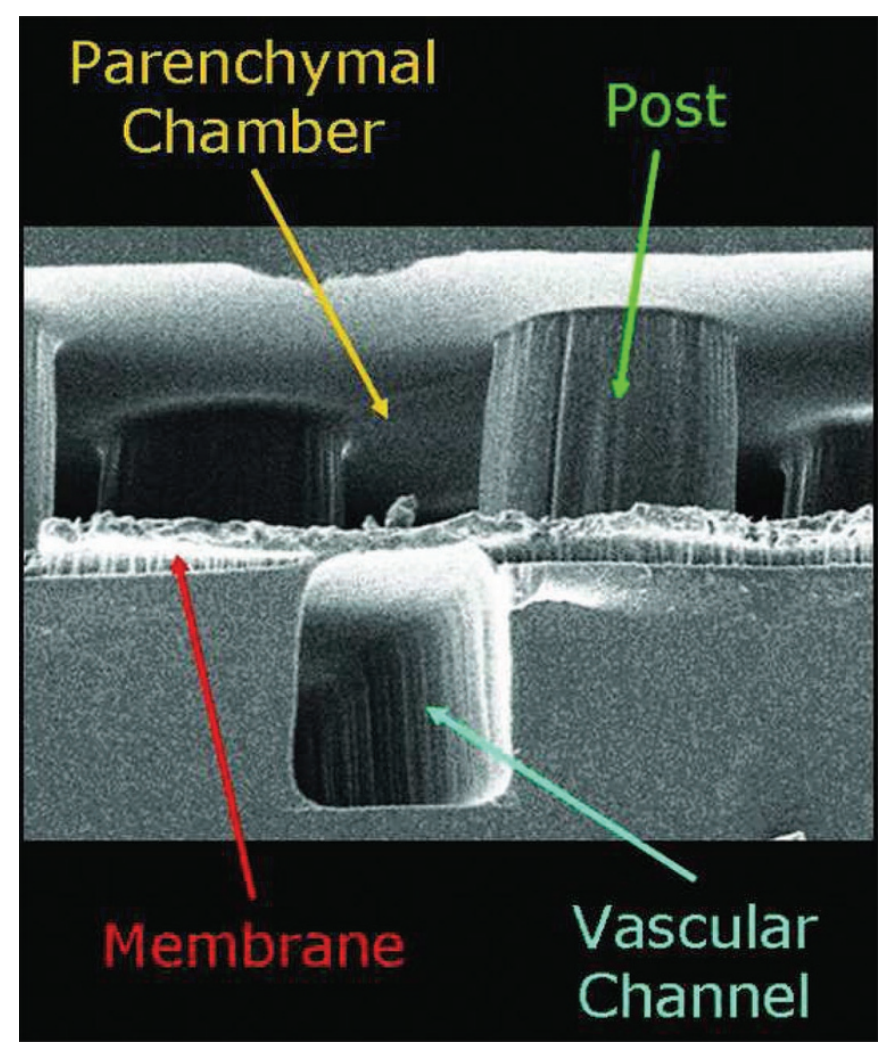

Figure 2. Cross-sectional image of vascular network channel and adjacent parenchymal chamber.

diameter, and flow rate of blood in each branch and in the vascular network as a whole. There is excellent correlation of this theory with distal coronary and pulmonary circulations. The correlation with arcade vascular structures such as the mesenteric arteries and the epicardial coronary arteries is not as strong. The vascular network designs proposed by this model exist in three dimensions similar to native vasculature. Although anatomically accurate, there will need to be a significant advance in tissueengineered scaffold development and manufacturing before such a design could be used.

Janakiraman et al. developed a theoretical vascular network to support tissue-engineered skin (17). This network was optimized for mass transport efficiency utilizing a conceptual porous material. The result is a symmetrical bifurcating design with up to six vascular generations. The conclusion is that rectangular ducts provide a more efficient transport of nutrients due to their increased surface to volume ratio over square shaped ducts. The work highlights an approach of utilizing computations to optimize the design of a vascular network.

Vozzi et al. and Bianchi et al. have developed a branching vascular network design based on Murray's Law and an allometric scaling scheme developed by West et al. (14,18-20). This planar design has been fabricated using an innovative method of precision polymer extrusion from a microsyringe. The result is a solid polymer fractal network made with a resorbable polymer, poly-lactide-co-glycolide. Endothelial cells and fibroblasts have been grown on the outside of the vascular network as a first step toward creating a microvascular scaffold. However, in vitro resorption of the polymer network to create a microvessel with a lumen has not been demonstrated.

Our vascular network, now in its third evolution, is based on biomimetic design parameters including asymmetric branching, physiologic branch lengths and bifurcation angles, and relative diameters of subsequent generations based on Murray's law. In addition to improvements in network design, the manufacturing of the network has advanced from a single depth vascular network created with photolithography to a three-dimensional planar network design utilizing an innovative manufacturing process. The result is a more physiologic vascular network that can be expanded both serially and in parallel and provides improved delivery of oxygen and nutrients to cells while minimizing the risk of thrombus formation in the network in vivo. The ongoing development of this vascularized scaffold continues to drive the ultimate focus of our lab, the development of tissue-engineered liver and lung constructs capable of replacing function at the organ level.

\section{LIVER}

The field of hepatic tissue engineering has the potential to address far reaching clinical problems from in-born errors of metabolism to chronic liver failure. After addressing the critical issue of immediately supplying cells with oxygen and nutrients the field is principally limited by one factor: the lack of an adequate supply of functional hepatocytes. The liver is composed of several distinct cell types, including hepatocytes, sinusoid endothelial, Kupffer, stellate, biliary epithelial, and pit cells. These cells are joined together through tight junctions and connective tissue such as type I and IV collagen and laminins (21). Hepatocytes are responsible for most clinically measurable organ functions including metabolic homeostasis, protein synthesis, and detoxification. The remaining nonparenchymal cells support parenchymal cellular orientation and function (22-24). Using a standard protocol for dissociating cells from liver tissue, several cell types have been isolated and evaluated for their potential as a source of cells for hepatic tissue engineering including primary animal hepatocytes, hepatocellular carcinoma (HepG2) cell lines, and human primary hepatocytes from normal liver $(25,26)$. 
Hepatocytes derived from the livers of nonhuman mammalian species are termed xenogenic cells. The prime advantage these cells offer is a virtually unlimited supply of primary hepatocytes under strictly controlled production conditions (27). This is particularly true of porcine hepatocytes because they exhibit metabolic characteristics similar to human hepatocytes, can be procured in large quantities, and stored for many months with minimal loss of viability (28). However, the use of these cells in tissue-engineering applications is controversial due to the risk of zoonotic transmission of diseases such as porcine endogenous retrovirus (29). In the European community, the concern for porcine endogenous retrovirus transmission is so great that The Advisory Group on the Ethics of Xenotransplantation and the Nuffield Council on Bioethics have recommended a complete European moratorium on the clinical use of xenogenic hepatocytes $(30,31)$. Despite the uncertain future of this cell source in the European community, The United States Public Health Service's Draft Public Health Service Guideline on Infectious Disease Issues in Xenotransplantation clearly supports xenogenic cell source research, provided that xenogenic tissues are prescreened for zoonotic disease before use and that patients in whom xenogenic cells have been implanted are followed long-term for signs of transmission (32). Based on the political climate surrounding these cells, it is unlikely that they will represent a near-term solution to the hepatocyte shortage and would likely be abandoned if a human source were identified (33). In addition, subtle differences in the metabolic response between animal and human hepatocytes are known to exist and these differences limit the performance of a tissue-engineered construct based on animal cells (34). Therefore, the ideal cell source for hepatic tissue engineering would clearly come from a human-derived source of hepatocytes.

The term "cell line" refers to human cells derived from metastatic tumors, which have become immortalized and demonstrate an unlimited capacity for growth in vitro. Within the field of hepatic tissue engineering, the most commonly used cell line is the C3A subclone of the HepG2 cell line $(28,35)$. These cells are commonly used in vitro and have a very hardy nature. They tolerate repeated freezing and thawing cycles and will readily proliferate in culture, which makes them very easy to use in the laboratory setting. This cell line continues to demonstrate some normal hepatic metabolic function including albumin synthesis, p450 activity, and urea synthesis. Unfortunately, this cell line has an abnormal metabolic profile $(36,37)$. One of the abnormal metabolic products of HepG2$\mathrm{C} 3 \mathrm{~A}$ cells is alpha-fetoprotein, which is often used as a marker of metabolic activity in HepG2-based tissue-engineering constructs (35). Because HepG2 cells are derived from a known malignant tumor, they present a risk for the development of metastases in any clinical application, and most likely will be relegated to use exclusively in in vitro tissue-engineering applications $(27,35,38)$.

Primary hepatocytes are fully mature adult hepatocytes that have been isolated from the extracellular matrix of human liver. These cells are the cells of greatest interest for hepatic tissue engineering and are broken down into two principal groups: allogenic primary hepatocytes and autologous primary hepatocytes. Allogenic primary hepatocytes are cells that are derived from human sources other than the patient for whom they are intended. Further, a tissue-engineered construct containing these cells would present all the immune risks of transplantation and could complicate the patient's future rejection risk should a traditional transplantation be required at a later time (33). Moreover, these human-derived cells pose a greater risk for potential disease transmission to a patient than animal cells. However, allogenic primary hepatocytes may represent the best cell population for tissue-engineering applications, given their unimpaired metabolic function and relatively large quantities compared with autologous primary hepatocytes (28).

Autologous primary human hepatocytes are the preferred alternative to allogenic primary hepatocytes because they are derived directly from the patient for whom any tissueengineered liver replacement therapy is intended (33). These cells already exhibit the same immunomarkers as the patient, eliminating the possibility of an immune rejection (28). However, although immunologically advantageous, the use of the patient's own cells has been considered an unsatisfactory solution to the cells source problem for two reasons. First, patients with liver dysfunction may not have the hepatic reserve to withstand the removal of hepatocytes in a separate procedure before the implantation of a tissue-engineered liver construct. Second, because these hepatocytes are already functioning poorly, once removed from the in vivo environment, they may lose function entirely (33).

An overriding limitation to the use of these cells is that primary human hepatocytes of either variety are very difficult to obtain in large quantities (39). In fact, primary human hepatocytes are hard to obtain at all. Only three potential sources exist: $a$ ) discarded liver removed before implantation of a liver transplant; $b$ ) surgically resected sections of a diseased liver (typically cancer); c) cells obtained from liver biopsy. In the first case, the organ dysfunction, which necessitated the transplant, may translate into a dysfunction on the cellular level and the scarring associated with the disease impairs the isolation of the cells for use in vitro. In addition, these grafts are only sporadically available and any organ considered unfit for use in transplantation may not contain many hepatocytes able to withstand processing for tissueengineering applications (27). In a liver specimen resected for a focal disease such as cancer or metastases, normal cells are found surrounding the lesion. These cells typically exhibit normal cellular function, but the goal of a resection is to minimize the mass of liver removed and therefore these cells are not plentiful. Biopsies, although far less invasive than a liver resection, yield a population of cells orders of magnitude smaller than the cells derived from a liver resection. Although all of these sources of hepatocytes could provide allogenic primary hepatocytes, the only clinically viable opportunity to obtain autologous primary hepatocytes from a patient with liver disease is via a biopsy specimen. Given their scarcity, primary human hepatocyte populations of both varieties have been expanded and preserved through the use of immortalization techniques involving temperature-sensitive SV40Tag, suicide genes, and Cre-lox P-mediated oncogene excision $(28,36,38)$. All of these techniques have shown promise in vitro 
but have failed to generate adequate amounts of functional tissue to be clinically applied at this time. Even if primary human hepatocytes were available in large quantities, a larger problem exists: primary human hepatocytes are difficult to maintain in culture for extended periods of time (40). The reason for this poor in vitro performance may be due to the processing required to isolate primary hepatocytes in the first place.

A standard protocol for dissociating cells from liver tissue of multiple species is based on the enzymatic dissociation of all the liver cells from the supporting extracellular matrix. The parenchymal and nonparenchymal components are separated to further isolate the specific cell populations $(25,26)$. When isolated in this manner, hepatocytes exhibit in vitro degradation in function and viability because hepatocytes require cell-to-cell contact to maintain their epidermal characteristics $(29,41)$. A novel source of tissue for hepatic tissue engineering that may avoid these limitations is the use of precision-cut liver slices.

As early as the mid 1980s, it was recognized that coculturing primary hepatocytes with other cells significantly improved in vitro survival (42). This observation eventually led to the evaluation of intact liver slices as a model for hepatic metabolism, and several benefits were recognized. Specifically, primary hepatocytes cultured in isolation become disorganized and detached early in culture (42); however, when co-cultured with nonparenchymal cells, primary hepatocytes survived for several weeks while retaining metabolic function (43). In addition, the liver has an enormous regenerative ability, which precision-cut liver slices may preserve (44). When primary hepatocytes regenerate in vivo they will proliferate several times until the mass and function of the organ is restored and then return to the $G_{0}$ state $(45,46)$. By comparison, primary hepatocytes procured through enzymatic dissociation replicate once or twice in vitro but then demonstrate steady decline and dedifferentiation (47). This observed difference may be due to the disruption of critical cell-to-cell and cell-to-matrix interactions, and implies that nonparenchymal cells and extracellular matrix are necessary for hepatocytes to proliferate and regain function. Precision-cut liver slices preserve the cell-to-cell and cell-to matrix contact of the tissue while recreating the proper ratios of nonparenchymal cells for co-culture (43). Unfortunately, slices of human liver are also extremely difficult to obtain and to be clinically relevant these slices would have to be induced to regenerate in vitro. To date this has not been successfully reported in the literature.

One promising source of future hepatocytes that has only recently been investigated comes from the field of stem cells. The term "stem cell" is broadly used to refer to undifferentiated cells of any species that meet the following criteria: 1) they can convert from their undifferentiated form into one or several specialized cell types and; 2) they continue to generate undifferentiated genetically identical daughter cells capable of future differentiation $(28,48)$. These cells may serve as the solution to the problems of inadequate quantity; poor in vitro longevity, and genetic incompatibility. Several sources of stem cells show promise for use in the field of tissue engineering including embryonic stem cells and adult mesenchymal stem cells, as well as, transdifferentiated adult mesenchymal stem cells $(36,49,50)$.
Embryonic stem cells are defined as cells obtained from the inner cell mass of the blastocyst stage of embryonic development and have been shown to differentiate into hepatocytes through the application of cytokines including activin A and hepatocyte growth factor (51-53). In a 2006 study by SotoGutierrez et al., murine embryonic stem cells differentiated into mature hepatocytes with significantly higher efficiency through co-culture with human nonparenchymal liver cells and were used to reverse liver failure in $90 \%$ hepatectomized mice (54). This study demonstrated the broad plasticity of embryonic stem cells, as well as the degree to which they can be regulated through interactions with their environment. Unfortunately, human stem cells of embryologic origin are unlikely to contribute significantly to the clinical applications of hepatic tissue engineering for two reasons. First, these cells require a great deal of technical expertise to differentiate and even in skilled hands typically result in mixed populations and low yields. More importantly, in the United States the subject of embryonic stem cell research has become so politicized that cells of this type are very tightly regulated. Adult stem cells may prove to be the answer to this critical supply of cells for research in general and hepatic tissue-engineering research specifically.

Adult mesenchymal stem cells (MSC) were originally identified in the connective tissue matrices of several species and have recently been found in human tissues that have a high cellular turnover rate throughout life such as bone marrow, blood, muscle, adipose, and dermis (55-59). Of these human sources, bone marrow-derived MSCs (BMSC) have been the most intensely investigated. It was originally thought that MSC differentiation was limited to the MSC germ layer of origin, but recent studies have called this thinking into question. Several reports have shown that adult stem cells can be "transdifferentiated" into cells not normally associated with their committed state (60). In 1999, Bjornson et al. demonstrated the conversion, or "fate switch" of neural stem cells into the hematopoietic lineage (61-67). In a 2004 study, Lee at al. demonstrated that BMSCs and MSCs from umbilical cord blood differentiated into hepatocytes with glycogen storage, synthetic capacity for $\alpha$-fetoprotein, urea and albumin, and inducible p450 function (68). Other examples include reports by Petersen et al. 1999 and Oh et al. in 2007 that demonstrated hematopoietic stem cells from bone marrow transdifferentiating from the mesenchymal lineage to an endothelial lineage ultimately expressing markers consistent with an hepatic cell type $(60,63,69)$. These promising preliminary studies indicate the enormous potential of stem cell technology in the field of hepatic tissue engineering. However, both of these cell sources have limitations associated with their use: umbilical blood is only available in small quantities; and the harvest of bone marrow involves a painful, invasive biopsy and has a variable yield (70).

Attention has recently been turned to adipose tissue as a potential source of cells for cellular therapies. It can be obtained in large quantities under local anesthesia with minimal patient discomfort (71). MSCs are present in much greater numbers in adipose tissue than bone marrow and have similar growth kinetics and expansion potential (72). Several studies have shown that MSCs from adipose (ADMSCs) can 
differentiate into osteogenic, adipogenic and chondrogenic lineages with equal or greater efficiency than BMSCs (72-75). Seo et al. showed that ADMSCs could be transformed into hepatocyte-like cells with morphology, albumin synthesis, urea production, and low-density lipids uptake, suggesting their potential as the primary cellular source for liver tissueengineering applications (76). These initial efforts to redirect ADMSCs down the hepatic lineage are promising; however, no definitive breakthrough has clearly indicated that these cells will relieve the critical shortage of hepatocytes facing the field of hepatic tissue engineering.

\section{LUNG}

Efforts to develop a tissue-engineered lung have only recently begun to gain momentum despite a significant clinical need. In the pediatric population, there is an unmet need for lung transplantation grafts. In 2006, there were 55 pediatric lungs transplanted, while the current waiting list is nearly three times that at 137 patients (77). In addition to the pediatric population, a tissue-engineered lung structure could have a significant impact in the adult population in which lung disease is a significant source of morbidity and mortality. Development of a tissueengineered lung would address this issue.

Recognition of the efficient transfer of oxygen and nutrients from the vascular chamber to the parenchymal chamber in the liver scaffold has led to a modification of this concept to create a scaffold for development of a tissue-engineered lung. The lung scaffold consists of a vascular network similar in concept to the liver vascular network. A thin, porous membrane separates the vascular network from an adjacent alveolar chamber, which has continuous oxygen flow. Oxygen and carbon dioxide are exchanged between the blood and the alveolar chamber across the membrane. Like the liver scaffold, this scaffold can be scaled up to achieve a desired total size, in this case the important end goal being surface area for gas exchange.

The gas exchange with this scaffold is significant. A single planar scaffold of this design with a surface area of $0.0018 \mathrm{~m}^{2}$ can achieve oxygen transfer of $0.17 \mathrm{~mL} / \mathrm{min}$ and carbon dioxide transfer of $0.16 \mathrm{~mL} / \mathrm{min}$ (data not published). If scaled up to meet the demands of a resting adolescent or young adult this would result in a lung scaffold with $2.8 \mathrm{~m}^{2}$ of surface area and oxygen transfer of $250 \mathrm{~mL} / \mathrm{min}$ and carbon dioxide transfer of $265 \mathrm{~mL} / \mathrm{min}$. With this early stage work, it certainly appears feasible to achieve significant gas transfer with a tissue-engineered lung scaffold. Significant optimization will lead to achievement of improved gas transfer to the meet the demands of an exercising young individual.

To date these scaffolds have been created using silicone or traditional resorbable biomaterials. These efforts have resulted in the effective scaffolds but the mass of polymer required per unit of tissue is significant. If implanted in vivo the scaffolds currently would be too thick to achieve the required lung surface area to support the respiratory needs of an individual. Efforts are currently underway to construct these scaffolds using naturally occurring extracellular matrix proteins, possibly combined with resorbable polymer. Early results suggest that this approach could reduce the thickness of the scaffolds to a more physiologic size.

The first step in testing these extracellular matrix proteins as scaffold material was to develop a resorbable membrane that could be positioned between the vascular network and the alveolar chamber. A thin collagen membrane has been developed for the lung scaffold. When endothelial cells are cultured on one side of the membrane and pneumocytes are culture on the opposite side, the membrane is functionally similar to the alveolar membrane or air-blood interface in the lung. When these membranes are tested in an in vitro gas exchange model, which utilizes flowing fresh blood past the membrane, oxygen and carbon dioxide transfer occurs across the membrane. Initial testing demonstrates that the $\mathrm{PO}_{2}$ in the blood increases after flowing by a collagen membrane with pneumocytes and endothelial cells (data not published). The $\mathrm{PCO}_{2}$ in the blood decreased under the same conditions. Although significant optimization is required, the combination of strength and thickness of thin collagen membranes and demonstration of gas transfer through them is an exciting step toward the creation of a tissue-engineered lung.

Other investigators have begun to explore strategies to develop engineered lung tissue. Cortiella et al. developed porous scaffolds with polyglycolic acid or Pluronic F-127 (PF-127) (78). These scaffolds were seeded with ovine somatic lung progenitor cells and grown in vitro and also implanted on the back of a nude mouse or into an ovine lung wedge resection site. Although the polyglycolic acid scaffold supported the growth of the lung cells in a sponge-like open porous structure in vitro, when implanted in vivo, the inflammatory reaction, which was generated in response to the polymer. However, when PF-127 and the somatic lung progenitor cells were implanted in these locations tissue developed which was morphologically similar to lung alveolar tissue. These results are promising steps toward the creation of distal lung tissue.

Andrade et al. also have achieved "alveolar-like structures" in an in vivo lung tissue-engineering model by employing a simple porous scaffold (79). In this work, Gelfoam sponges were seeded with fetal rat pneumocytes and injected into a healthy lung of a rat. The sponges were still present at $60 \mathrm{~d}$ with an open porous structure within the sponge resembling native lung alveoli. Angiogenesis occurred in the sponge evidenced by vascular structures, which were in communication with native lung vessels. This study again highlights the ability of native lung cells to regenerate into a morphogenic lung structure.

In similar in vitro work, Chen et al. achieved alveolar-like structures by growing fetal rat lung cells on a collagenglycosaminoglycan tissue-engineered scaffold (80). At 2 wk, 50-60 $\mu \mathrm{m}$ alveolar-like structures were present in this open porous scaffold.

These studies have demonstrated that morphogenically characteristic lung tissue can be formed using lung cells and open porous scaffolds. This progress and the demonstration of significant gas exchange in prospectively designed vascularized scaffolds in our lab are exciting advances in this budding area of lung tissue engineering. Future efforts will hopefully 
advance both of these approaches and perhaps achieve a tissue structure, which could be used to address the clinical needs of pulmonary failure in the pediatric population.

Unlike the liver, lung support technologies to date have not used cellular material. Thus, the consideration of sources of lung cells for tissue-engineered lung applications has not yet been addressed as widely in the literature. Several possibilities exist including autologous or allogeneic lung cells expanded in vitro. Researchers have demonstrated the derivation of type II pneumocytes from human embryonic stem cells (81). This or other stem-cell-based approaches may be feasible.

Perhaps the most significant impact tissue-engineered lung development could have on the pediatric population is the creation of a respiratory device for preterm infants. Utilizing the vascularized scaffold approach, a tissue-engineered lung is being developed as an external temporary lung replacement device. Lung insufficiency and respiratory failure are the leading cause of death in preterm infants. Lungs of preterm infants are underdeveloped and can be significantly damaged with standard ventilation practices, which are currently necessary for the infant's survival.

Our approach is to develop a tissue-engineered lung, which could completely support the infant for weeks or months following birth. This technology would obviate the need to intubate preterm infants at birth. Following birth of a preterm infant, the umbilical vein and umbilical artery would be immediately cannulated and these vessels would be the blood supply and return for the tissue-engineered lung. For this approach, the tissue-engineered lung scaffold would need to include a completely endothelialized vascular network so blood could flow through the scaffold without the need for any anticoagulation of the infant. This would make the therapy available to any gestational age or weight infant. Extracorporeal membrane oxygenation is alternative means of lung support in premature infants but has traditionally not been used in low-birth-weight infants due to the risk of hemorrhage in this patient population. Although recent data suggests that extracorporeal membrane oxygenation can be used in infants with birth weight as low as $1.6 \mathrm{~kg}$, the incidence of hemorrhage and intracranial bleeding is higher in this patient population (82). In theory, an endothelialized tissue-engineered lung will overcome this limitation by avoiding anticoagulation. Many factors surrounding this approach remain unanswered including the persistence of fetal circulation ex utero. Despite the technological and physiologic challenges ahead, this approach may be a solution to reducing the respiratory morbidity and mortality of preterm infants.

The field of tissue engineering has the potential to provide a myriad of tissues for future clinical applications. At present, the only tissues in clinical use have low metabolic rates such as bone, cartilage, and skin. However, a vascularized scaffold will likely be required for the clinical replacement of a highly metabolic tissue such as a solid organ. Such a structure should be the focus of research for the development of a tissueengineered liver or lung.

\section{REFERENCES}

1. Yannas IV, Burke JF, Orgill DP, Skrabut EM 1982 Wound tissue can utilize a polymeric template to synthesize a functional extension of skin. Science 215:174176

2. Weinberg CB, Bell E 1986 A blood vessel model constructed from collagen and cultured vascular cells. Science 231:397-400

3. Vacanti JP 1988 Beyond transplantation. Third annual Samuel Jason Mixter lecture. Arch Surg 123:545-549

4. Vacanti JP, Morse MA, Saltzman WM, Domb AJ, Perez-Atayde A, Langer R 1988 Selective cell transplantation using bioabsorbable artificial polymers as matrices. J Pediatr Surg 23:3-9

5. Kim SS, Utsunomiya H, Koski JA, Wu BM, Cima MJ, Sohn J, Mukai K, Griffith LG, Vacanti JP 1998 Survival and function of hepatocytes on a novel three-dimensional synthetic biodegradable polymer scaffold with an intrinsic network of channels. Ann Surg 228:8-13

6. Griffith LG, Wu B, Cima MJ, Powers MJ, Chaignaud B, Vacanti JP 1997 In vitro organogenesis of liver tissue. Ann N Y Acad Sci 831:382-397

7. Borenstein JT, Weinberg EJ, Orrick BK, Sundback C, Kaazempur-Mofrad MR, Vacanti JP 2007 Microfabrication of three-dimensional engineered scaffolds. Tissue Eng 13:1837-1844

8. Fidkowski C, Kaazempur-Mofrad MR, Borenstein J, Vacanti JP, Langer R, Wang Y 2005 Endothelialized microvasculature based on a biodegradable elastomer. Tissue Eng 11:302-309

9. Kaihara S, Borenstein J, Koka R, Lalan S, Ochoa ER, Ravens M, Pien H, Cunningham B, Vacanti JP 2000 Silicon micromachining to tissue engineer branched vascular channels for liver fabrication. Tissue Eng 6:105-117

10. Khademhosseini A, Langer R, Borenstein J, Vacanti JP 2006 Microscale technologies for tissue engineering and biology. Proc Natl Acad Sci USA 103:2480-2487

11. Ogawa K, Ochoa ER, Borenstein J, Tanaka K, Vacanti JP 2004 The generation of functionally differentiated, three-dimensional hepatic tissue from two-dimensional sheets of progenitor small hepatocytes and nonparenchymal cells. Transplantation 77:1783-1789

12. Shin M, Matsuda K, Ishii O, Terai H, Kaazempur-Mofrad M, Borenstein J, Detmar M, Vacanti JP 2004 Endothelialized networks with a vascular geometry in microfabricated poly(dimethyl siloxane). Biomed Microdevices 6:269-278

13. Weinberg EJ, Borenstein JT, Kaazempur-Mofrad MR, Orrick B, Vacanti JP 2004 Design and fabrication of a constant shear microfluidic network for tissue engineering. Materials Research Society Symposium, Materials Research Society Press, Warrendale, PA, p 121

14. Murray CD 1926 The physiological principle of minimum work. I. The vascular system and the cost of blood volume. Proc Natl Acad Sci USA 12:207-214

15. Zhou Y, Kassab GS, Molloi S 1999 On the design of the coronary arterial tree: a generalization of Murray's law. Phys Med Biol 44:2929-2945

16. Kassab GS 2006 Scaling laws of vascular trees: of form and function. Am J Physiol Heart Circ Physiol 290:H894-H903

17. Janakiraman V, Mathur K, Baskaran H 2007 Optimal planar flow network designs for tissue engineered constructs with built-in vasculature. Ann Biomed Eng 35:337347

18. Vozzi G, Previti A, Ciaravella G, Ahluwalia A 2004 Microfabricated fractal branching networks. J Biomed Mater Res A 71:326-333

19. West GB, Brown JH, Enquist BJ 1997 A general model for the origin of allometric scaling laws in biology. Science 276:122-126

20. Bianchi F, Rosi M, Vozzi G, Emanueli C, Madeddu P, Ahluwalia A 2007 Microfabrication of fractal polymeric structures for capillary morphogenesis: applications in therapeutic angiogenesis and in the engineering of vascularized tissue. J Biomed Mater Res B Appl Biomater 81:462-468

21. Crawford JM 1999 The Liver and Biliary Tract. In: Cotran RS, Kumar V, Collins T (eds) Robbins Pathologic Basis of Disease. W.B. Saunders Company, Philadelphia, PA, pp 845-901

22. Jungermann K, Katz N 1982 Functional hepatocellular heterogeneity. Hepatology 2:385-395

23. Jungermann K, Katz N 1989 Functional specialization of different hepatocyte populations. Physiol Rev 69:708-764

24. LeCluyse EL, Audus KL, Hochman JH 1994 Formation of extensive canalicular networks by rat hepatocytes cultured in collagen-sandwich configuration. Am J Physiol 266:C1764-C1774

25. Seglen PO 1972 Preparation of rat liver cells. I. Effect of Ca $2+$ on enzymatic dispersion of isolated, perfused liver. Exp Cell Res 74:450-454

26. Kulig KM, Vacanti JP 2004 Hepatic tissue engineering. Transpl Immunol 12:303310

27. Ichai P, Samuel D 2004 Treatment of patients with hepatic failure: the difficult place of liver support systems. J Hepatol 41:694-695

28. Krebs N, Neville C, Vacanti J 2007 Cellular transplantation for liver diseases. In: Halberstadt C, Emerich D (eds) Cellular Transplantation from Laboratory to Clinic. Academic Press, Burlington, MA, pp 215-240

29. Demetriou AA, Brown RS Jr., Busuttil RW, Fair J, McGuire BM, Rosenthal P, Am Esch JS II, Lerut J, Nyberg SL, Salizzoni M, Fagan EA, de Hemptinne B, Broelsch CE, Muraca M, Salmeron JM, Rabkin JM, Metselaar HJ, Pratt D, De La Mata M, McChesney LP, Everson GT, Lavin PT, Stevens AC, Pitkin Z, Solomon BA 2004 Prospective, randomized, multicenter, controlled trial of a bioartificial liver in treating acute liver failure. Ann Surg 239:660-667, discussion 667-670

30. Bioethics NCo 1996 Animal-to-Human Transplants: The Ethics of Xenotransplantation. Nuffield Council on Bioethics, London, England, pp 1-122 
31. Kennedy I 1997 Animal Tissue into Humans: A Report by the Advisory Group on the Ethics of Xenotransplantation. The Stationery Office Books, Norwich, England, p 284

32. U.S. Public Health Service 1996 Draft Public Health Service Guideline on Infectious Disease Issues in Xenotransplantation (August 1996); notice. Fed Regist 61:4991949932

33. Pryor HI II, Vacanti JP 2008 The promise of artificial liver replacement. Front Biosci $13: 2140-2159$

34. Xu JJ, Diaz D, O'Brien PJ 2004 Applications of cytotoxicity assays and pre-lethal mechanistic assays for assessment of human hepatotoxicity potential. Chem Biol Interact 150:115-128

35. Kelly JH, Sussman NL 1994 The hepatix extracorporeal liver assist device in the treatment of fulminant hepatic failure. ASAIO J 40:83-85

36. Allen JW, Hassanein T, Bhatia SN 2001 Advances in bioartificial liver devices. Hepatology 34:447-455

37. Tirmenstein MA, Hu CX, Gales TL, Maleeff BE, Narayanan PK, Kurali E, Hart TK, Thomas HC, Schwartz LW 2002 Effects of troglitazone on HepG2 viability and mitochondrial function. Toxicol Sci 69:131-138

38. Allen JW, Bhatia SN 2002 Improving the next generation of bioartificial live devices. Semin Cell Dev Biol 13:447-454

39. Hengstler JG, Brulport M, Schormann W, Bauer A, Hermes M, Nussler AK, Fandrich F, Ruhnke M, Ungefroren H, Griffin L, Bockamp E, Oesch F, von Mach MA 2005 Generation of human hepatocytes by stem cell technology: definition of the hepatocyte. Expert Opin Drug Metab Toxicol 1:61-74

40. Ishizaka S, Shiroi A, Kanda S, Yoshikawa M, Tsujinoue H, Kuriyama S, Hasuma T, Nakatani K, Takahashi K 2002 Development of hepatocytes from ES cells after transfection with the HNF-3beta gene. FASEB J 16:1444-1446

41. Grant MH, Morgan C, Henderson C, Malsch G, Seifert B, Albrecht W, Groth T 2005 The viability and function of primary rat hepatocytes cultured on polymeric membranes developed for hybrid artificial liver devices. J Biomed Mater Res A 73:367375

42. Fautrel A, Joly B, Guyomard C, Guillouzo A 1997 Long-term maintenance of drug-metabolizing enzyme activities in rat hepatocytes after cryopreservation. Toxicol Appl Pharmacol 147:110-114

43. de Kanter R, Monshouwer M, Meijer DK, Groothuis GM 2002 Precision-cut organ slices as a tool to study toxicity and metabolism of xenobiotics with special reference to non-hepatic tissues. Curr Drug Metab 3:39-59

44. Higgins GM, Anderson RM 1931 Experimental pathology of the liver. I. Restoration of the liver of the white rat following partial surgical removal. Arch Pathol 12:186-202

45. Alison MR 1986 Regulation of hepatic growth. Physiol Rev 66:499-541

46. Fausto N 2000 Liver regeneration. J Hepatol 32:19-31

47. Etienne PL, Baffet G, Desvergne B, Boisnard-Rissel M, Glaise D, Guguen-Guillouzo C 1988 Transient expression of c-fos and constant expression of c-myc in freshly isolated and cultured normal adult rat hepatocytes. Oncogene Res 3:255-262

48. Davila JC, Cezar GG, Thiede M, Strom S, Miki T, Trosko J 2004 Use and application of stem cells in toxicology. Toxicol Sci 79:214-223

49. Zuk PA, Zhu M, Ashjian P, De Ugarte DA, Huang JI, Mizuno H, Alfonso ZC, Fraser JK, Benhaim P, Hedrick MH 2002 Human adipose tissue is a source of multipotent stem cells. Mol Biol Cell 13:4279-4295

50. Zuk PA, Zhu M, Mizuno H, Huang J, Futrell JW, Katz AJ, Benhaim P, Lorenz HP, Hedrick MH 2001 Multilineage cells from human adipose tissue: implications for cell-based therapies. Tissue Eng 7:211-228

51. Martin GR 1981 Isolation of a pluripotent cell line from early mouse embryos cultured in medium conditioned by teratocarcinoma stem cells. Proc Natl Acad Sci USA 78:7634-7638

52. Nagy A, Gocza E, Diaz EM, Prideaux VR, Ivanyi E, Markkula M, Rossant J 1990 Embryonic stem cells alone are able to support fetal development in the mouse. Development 110:815-821

53. Chen Y, Soto-Gutierrez A, Navarro-Alvarez N, Rivas-Carrillo JD, Yamatsuji T, Shirakawa Y, Tanaka N, Basma H, Fox IJ, Kobayashi N 2006 Instant hepatic differentiation of human embryonic stem cells using activin A and a deleted varian of HGF. Cell Transplant 15:865-87

54. Soto-Gutierrez A, Navarro-Alvarez N, Zhao D, Rivas-Carrillo JD, Lebkowski J, Tanaka N, Fox IJ, Kobayashi N 2007 Differentiation of mouse embryonic stem cells to hepatocyte-like cells by co-culture with human liver nonparenchymal cell lines. Nat Protoc 2:347-356

55. Potten CS, Loeffler M 1990 Stem cells: attributes, cycles, spirals, pitfalls and uncertainties. Lessons for and from the crypt. Development 110:1001-1020

56. Schwartz RE, Reyes M, Koodie L, Jiang Y, Blackstad M, Lund T, Lenvik T, Johnson S, Hu WS, Verfaillie CM 2002 Multipotent adult progenitor cells from bone marrow differentiate into functional hepatocyte-like cells. J Clin Invest 109:1291-1302

57. Lee RH, Kim B, Choi I, Kim H, Choi HS, Suh K, Bae YC, Jung JS 2004 Characterization and expression analysis of mesenchymal stem cells from human bone marrow and adipose tissue. Cell Physiol Biochem 14:311-324
58. Young HE, Ceballos EM, Smith JC, Mancini ML, Wright RP, Ragan BL, Bushell I, Lucas PA 1993 Pluripotent mesenchymal stem cells reside within avian connective tissue matrices. In Vitro Cell Dev Biol Anim 29A:723-736

59. Young HE, Mancini ML, Wright RP, Smith JC, Black AC Jr, Reagan CR, Lucas PA 1995 Mesenchymal stem cells reside within the connective tissues of many organs. Dev Dyn 202:137-144

60. Fuchs E, Segre JA 2000 Stem cells: a new lease on life. Cell 100:143-155

61. Bjornson CR, Rietze RL, Reynolds BA, Magli MC, Vescovi AL 1999 Turning brain into blood: a hematopoietic fate adopted by adult neural stem cells in vivo. Science 283:534-537

62. Theise ND, Nimmakayalu M, Gardner R, Illei PB, Morgan G, Teperman L, Henegariu O, Krause DS 2000 Liver from bone marrow in humans. Hepatology 32:11-16

63. Petersen BE, Bowen WC, Patrene KD, Mars WM, Sullivan AK, Murase N, Boggs SS, Greenberger JS, Goff JP 1999 Bone marrow as a potential source of hepatic oval cells. Science $284: 1168-1170$

64. Jang YY, Collector MI, Baylin SB, Diehl AM, Sharkis SJ 2004 Hematopoietic stem cells convert into liver cells within days without fusion. Nat Cell Biol 6:532-539

65. Alison MR, Poulsom R, Jeffery R, Dhillon AP, Quaglia A, Jacob J, Novelli M, Prentice G, Williamson J, Wright NA 2000 Hepatocytes from non-hepatic adult stem cells. Nature 406:257

66. Ong SY, Dai H, Leong KW 2006 Inducing hepatic differentiation of human mesenchymal stem cells in pellet culture. Biomaterials 27:4087-4097

67. Shu SN, Wei L, Wang JH, Zhan YT, Chen HS, Wang Y 2004 Hepatic differentiation capability of rat bone marrow-derived mesenchymal stem cells and hematopoietic stem cells. World J Gastroenterol 10:2818-2822

68. Lee KD, Kuo TK, Whang-Peng J, Chung YF, Lin CT, Chou SH, Chen JR, Chen YP, Lee OK 2004 In vitro hepatic differentiation of human mesenchymal stem cells. Hepatology 40:1275-1284

69. Oh SH, Witek RP, Bae SH, Zheng D, Jung Y, Piscaglia AC, Petersen BE 2007 Bone marrow-derived hepatic oval cells differentiate into hepatocytes in 2-acetylaminofluorene/partial hepatectomy-induced liver regeneration. Gastroenterology 132:10771087

70. Pittenger MF, Mackay AM, Beck SC, Jaiswal RK, Douglas R, Mosca JD, Moorman MA, Simonetti DW, Craig S, Marshak DR 1999 Multilineage potential of adult human mesenchymal stem cells. Science 284:143-147

71. Schaffler A, Buchler C 2007 Concise review: adipose tissue-derived stromal cellsbasic and clinical implications for novel cell-based therapies. Stem Cells 25:818827

72. De Ugarte DA, Morizono K, Elbarbary A, Alfonso Z, Zuk PA, Zhu M, Dragoo JL, Ashjian P, Thomas B, Benhaim P, Chen I, Fraser J, Hedrick MH 2003 Comparison of multi-lineage cells from human adipose tissue and bone marrow. Cells Tissues Organs 174:101-109

73. Kern S, Eichler H, Stoeve J, Kluter H, Bieback K 2006 Comparative analysis of mesenchymal stem cells from bone marrow, umbilical cord blood, or adipose tissue. Stem Cells 24:1294-1301

74. Song HY, Jeon ES, Kim JI, Jung JS, Kim JH 2007 Oncostatin M promotes osteogenesis and suppresses adipogenic differentiation of human adipose tissuederived mesenchymal stem cells. J Cell Biochem 101:1238-1251

75. Talens-Visconti R, Bonora A, Jover R, Mirabet V, Carbonell F, Castell JV, GomezLechon MJ 2006 Hepatogenic differentiation of human mesenchymal stem cells from adipose tissue in comparison with bone marrow mesenchymal stem cells. World J Gastroenterol 12:5834-5845

76. Seo MJ, Suh SY, Bae YC, Jung JS 2005 Differentiation of human adipose stroma cells into hepatic lineage in vitro and in vivo. Biochem Biophys Res Commun $328: 258-264$

77. Sharing UNfO 2007 UNet Database. http://www.optn.org/latestData/rptData.asp. Accessed March 18, 2008.

78. Cortiella J, Nichols JE, Kojima K, Bonassar LJ, Dargon P, Roy AK, Vacant MP, Niles JA, Vacanti CA 2006 Tissue-engineered lung: an in vivo and in vitro comparison of polyglycolic acid and pluronic F-127 hydrogel/somatic lung progenitor cell constructs to support tissue growth. Tissue Eng 12:1213-1225

79. Andrade CF, Wong AP, Waddell TK, Keshavjee S, Liu M 2007 Cell-based tissue engineering for lung regeneration. Am J Physiol Lung Cell Mol Physiol 292:L510 L518

80. Chen P, Marsilio E, Goldstein RH, Yannas IV, Spector M 2005 Formation of lung alveolar-like structures in collagen-glycosaminoglycan scaffolds in vitro. Tissue Eng 11:1436-1448

81. Samadikuchaksaraei A, Cohen S, Isaac K, Rippon HJ, Polak JM, Bielby RC, Bishop AE 2006 Derivation of distal airway epithelium from human embryonic stem cells. Tissue Eng 12:867-875

82. Rozmiarek AJ, Qureshi FG, Cassidy L, Ford HR, Gaines BA, Rycus P, Hackam DJ 2004 How low can you go? Effectiveness and safety of extracorporeal membrane oxygenation in low-birth-weight neonates. J Pediatr Surg 39:845-847 